\title{
Reflections
}

\section{Rights in education: outlines for a decolonial, childist reimagination of the future - commentary to Ansell and colleagues}

\author{
TATEK ABEBE AND TANU BISWAS
}

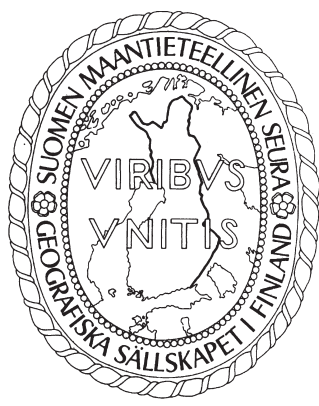

Abebe, T. \& Biswas, T. (2021) Rights in education: outlines for a decolonial, childist reimagination of the future - commentary to Ansell and colleagues. Fennia 199(1) 118-128. https://doi.org/10.11143/fennia.102004

In this piece, we reflect upon a recent article published in Fennia by Ansell and colleagues. We identify and discuss aspects of learning that educational research, policies and institutions can consider, addressing the needs and subjectivities of learners and activating a politics around rights in education. Rights in education foreground the intrinsic value of learning, inviting us to realign the purpose of education with the overall purpose of life on this planet. It pursues a 'bottom-up' strategy for rethinking education as community formation to incorporate complex sources of knowledge and modes of knowing and becoming for children. In order to think about rights in education, we uphold an analytical distinction between schooling and education. The distinction enables us to raise some questions, reflect on them and suggest preliminary ideas for decolonial, childist strategies to envisage education, highlighting how education and the 'future' are intimately woven and exploring what they mean for each other and for childhood. We do so particularly by critiquing 'western schooling' as a mode of learning which is a conspirator of capitalism deeply rooted in philosophical racism and contributing to a global epistemological loss. Finally, we outline four strategies of moving forward with a decolonial, childist lens of reimagining education as community formation and welcome further discussions on rights in education.

Keywords: rights in education, childhood, future, decoloniality, childism, community formation

Tatek Abebe (https://orcid.org/0000-0003-3811-0486), Department of Education and Lifelong Learning, Norwegian University of Science and Technology, Paviljong A, Dragvoll Loholt Alle 7049 Trondheim, Norway. E-mail: tatek.abebe@ntnu.no

Tanu Biswas (https://orcid.org/0000-0003-4498-8703), Department of Philosophy, University of Bayreuth, Universitätsstr. 30, 95447 Bayreuth, Germany. E-mail: biswas.tanushree@gmail.com 


\section{Introduction}

The article by Ansell and colleagues (2020), on which this commentary is based, demonstrates how schooling in rural peripheries of the global south perversely engages 'aspiration' only to generate paradoxical outcomes for children and young people. One of these paradoxes is that whereas schooling is a privileged practice through which new social possibilities and futures can be imagined, it works as a hegemonic institution that shapes and often stifles creativity and ethical-moral alternatives. A second paradox is that although education is considered a basic human right, it is realized by making schooling an obligation that children cannot easily refuse. Nor is what children learn in schools something that is co-developed in ways that attends to their needs and subjectivities. Another paradox is that the task of educating future citizens in a common institutional framework is understood as means to equalize social and economic differences. Yet, ongoing processes of privatizing and commodifying education contributes to a reality in which schooling increases social and economic inequalities not only of the present generation but also for the future. A further paradox is the discrepancy between the (opportunity) cost of educating children in schools, especially for low-income families and communities such as those in Laos, India and Lesotho; and the insecurity and uncertainties - and sometimes 'disjuncture' - about children's educational outcomes and successes.

Ansell and colleagues (2020) ask the important questions as to why, despite these paradoxes, schooling is invested upon and remains overloaded with economic, moral and economic expectations and hopes. Which processes sustain schooling as a social investment and as a privileged model of education for children in the rural peripheries of the global south? How and why the conditions of exclusion from the global economy and production of surplus populations continue to be facilitated by the project of schooling? The articles' theorization on how schooling produces subjects who are alienated from their communities' ways of life and livelihoods draws attention to what other, possibly relevant, knowledge systems are 'out there' that are not part of schooling, and consequently remain unacknowledged as education. Global agendas on Education for All (EFA) and United Nations development goals like Millennium Development Goals (MDGs) and Sustainable Development Goals (SDGs) that have re-scripted the purpose of education globally, pressure nations and their citizens to align themselves with a template of western schooling that is presumed to work everywhere. Schooling is a mode of learning deeply rooted in and historically resonating with western colonial culture and practices of knowledge transmission, contributing to the 'exclusion' of a vast range of knowledge systems and traditions. The point with this critique is that the tendency to formalize or standardize that which is otherwise informal, or 'the everyday,' has failed children and young people in many social and cultural contexts of the global south. At the same time, as some of the most privileged school-children in the world are now going on school strikes for climate justice - asking whether the time they spend in school is pointless in the face of the planetary crisis - we begin to question whether this model serves children in the global north too.

In this reflection piece, we build on these concerns of appropriate, relevant, and contextual learning for the future. We uphold the significance of activating debates around rights in education and facilitating a re-engagement with complex knowledge systems that are otherwise marginal or are excluded from mainstream knowledge economy. We do so by embracing powerful impulses from decolonial proponents and engaging with the education as community formation using the childist lens. Our reflection begins by considering schooling through a critical decolonial lens which is not limited to the global south and concerns a north-south continuum. We then discuss the potential of the rights in education framework in challenging global knowledge orders that privilege schooling as a singular form of 'education' based on the supremacy of 'white scientific knowledge'. That takes us to making a case for broadening pathways to rely on pluralist indigenous philosophies to re-imagine education, childhood and future. Finally, we discuss education as community formation in recognizing that in pursuing pluralist indigenous philosophies we risk embracing a regressive ideal of education that reinforces adult-child hierarchies. In conclusion, we propose four preliminary strategies and welcome engagement from stakeholders within the promising framework of rights in education. 


\section{Schooling through the decolonial lens of global epistemic (in-)justice}

The valorization of schooling as an educational practice superior to other ways of knowing and learning reflects the unequal power relations that engender the paradoxes of schooling. In recent years, the notion of cultural imperialism has been invoked as a warning that knowledge and practices of international development (including global development goals and EFA initiatives) are, in fact, historically specific to the western world and do not necessarily reflect the realities of children elsewhere. Postcolonial scholars have proposed the term 'epistemological violence' to highlight hegemonic cultural interpretations of scientific knowledge that construct the 'Other' as problematic or inferior, with implicit or explicit negative consequences for the 'Other' (Teo 2008; Mbembe 2016). As Serpell (2018) argues, the institutionalized public systems of schooling that draw on competitive, capitalist values not only promote an extractive definition of success but also inflict violence by stigmatizing unschooled children as 'incomplete' and 'incompetent'. Schoolchildren who are intellectually competent by indigenous cultural criteria but did not meet the official criteria for progression to the next grade often attribute their educational 'failure' to personal shortcomings (ibid.). Santos (2014) argues further that the struggle for social justice today needs to move beyond addressing political and economic inequalities to also attend to 'cognitive justice' or 'epistemic justice'. He notes that much of the knowledge produced in colonized and post-colonized societies has been incorporated into the mainstream school knowledge economy only marginally. Contemporary schooling renders certain types of knowledge invisible, unlearned, silenced, ignored, or made irrelevant. This failure to include the knowledge systems of certain communities and societies or perceiving their knowledge as "pagan, mystic, non-scientific" - "epistemicide" (Santos 2014, 30) - is a pervasive problem that represents the depoliticisation of knowledge and learning itself.

Schooling propels childhood to an imagined future, viewing children as 'embodiments of the future' and a site of social investment (Kjørholt 2013). Yet, the significance of schooling and what it teaches children is also nested in the culture and history of society. Arguably, western schooling produces future workers who are servants of capitalism regardless of where in the world they are schooled. As Ansell and colleagues (2020) systematically show with comparative examples from Laos, Lesotho and India, schooling in the global south particularly produces subjects who are in many ways a "surplus population" that is not necessary for the global capitalist economy or as Katz $(2011,58)$ puts it subjects who are rendered a "waste". The future-working-child is meant to be schooled, but not educated so that she can be deployed into labor whenever needed. However, she is often dismissed and replaced or sits idle, hoping for fitting opportunities to arise that match her ever-increasing aspirations. This reality has crystalized in the world-wide problem of schooled unemployed youth who scramble for precarious jobs (Jeffery 2005; Jeffrey et al. 2010; Clemens \& Biswas 2019). Research also shows how schooling alienates children from rural futures and the physical environment, contributing to a decline in their skills for resource conservation and environmental management (Abebe 2020; Biswas \& Sharma forthcoming). This is not only because children have limited access to land as they come of age, but they are also learning about land in a socio-historical context that is characterized by rapid population growth, land-grabbing, deforestation, and environmental degradation.

The destruction of the physical environment heightens young people's sense of displacement from the future. Katz (2004) argues that this displacement is a consequence of rural communities' insertion into the capitalist system that erodes existing patterns of social reproduction. Thus, children learn farming or herding, but they have no land on which to do it, or they attend school long enough to learn skills that are inappropriate for non-agricultural employment (ibid). Yet, as Ansell and colleagues (2020) show, schooling also stimulates unattainable aspirations and what Durham (2017) calls "elusive adulthoods". The problem of schooled unemployment and elusive adulthoods whereby young people struggle to achieve their socio-economic aspirations are interlinked with the academization of education'. Schooling represents the academicization of education - a reductive practice that contributes to the 'narrowing' of knowledge (also see Biesta 2015; Fitzsimons 2002). In other words, we find that schooling abstracts societal knowledge in ways that disconnects learners from local realities. This abstraction of knowledge, in turn, contributes to the narrowing of complex knowledge systems that cannot be 'scholarized'. 
We argue that schooling is inherently a western epistemological project in which Eurocentric systems of thought are imposed upon and expected to presumably alter, 'tame' or 'civilize' the subaltern and her ways of existing. We are particularly agitated by the pluralistic modes of knowing, doing, and becoming that have been erased and continue to be erased by the universal promotion of mass schooling under the pretext of fulfilling a 'right to education' which, in fact, concerns only the 'right to schooling'. We mourn the alternative futures of childhoods that have been irrecoverably displaced due to the 'ideal white pupil' model and, as a result, the various meaningful versions of childhoods that have not been envisioned in both the global south and the global north. Drawing upon critical comparative insights provided by Ansell and colleagues (2020) and our respective scholarships on education and childhood over the past years, we find that schooling has contributed to taking children out of community forming economies globally. This involves not only spatiotemporal standardization of community life but also of childhood and children's time so that their task is re-scripted to become only participation in institutionalized public schooling. Yet, the incompatibility of the school calendar with communal agricultural work cycles engenders the ways compulsory schooling, for example, renders children - who must be absent from classes for sustaining the local economy of coffee production in Ethiopia - as being problematic, 'delinquents' and 'truants' (Abebe 2011, 2015). Nieuwenhuys (1994) similarly argues that formal education led Indian children's life to be more burdensome as it did not relieve them from contributing to familial livelihoods but instead was added on top of those activities. These paradoxes imply the economic and cultural significance of childhood to society and reimagination of what meaningful education for children could be, invoking ideas of rights in education.

\section{Rights in education}

We are interested in how communities strategize and push back against the supremacy of 'white scientific knowledge' and the privileging of schooling as a singular form of 'education'. That is to say, the ways young people and their communities fight for rights 'in' education and not just right 'for' education. Rights in education evokes questions that not only challenge the global knowledge order but also inscriptions of new practices through the mediums of resistance/revolution/activism so as to re-politicize knowledge and re-introduce it in the debates around epistemic justice.

The ruptures in social reproduction require solutions in the projects of development and schooling by reorienting educational institutions as sites for reimagining learning. Given that promises of education for a better future are not met, it is time to rethink education outside the neoliberal paradigm and delink schooling from market-driven requirements of the capitalist economy (Ansell et al. 2020). A similar impulse comes from young climate activists from some of the most privileged welfare states in the world; young activists for whom neither the right to schooling, nor future income appears to be under threat. Despite their materially privileged positions they choose to go on school strike and question the hours demanded of them in school, because the current fossil-fueled neoliberal economy puts the future right to life for them and future generations into threat. Their indirect challenge to economic priorities of their governments, too, persuades us to move away from the discourse of rights 'to' education to instead inscribing rights 'in' education. Rights in education activates an onto-epistemological politics that attaches intrinsic value to life and realigns the purpose of education with the overall purpose of sustaining life on the planet. Unlike the right to education, which is about access, rights in education attend to the basic social, economic, cultural and gendered needs and subjectivities of learners as part of community formation processes. It draws attention to alternative strategies of intergenerational sharing of knowledge which seem to be neglected in the age-segregated context of schooling. Rights in education proposes to define schooling curricula upward by including educational goals such as social justice, citizenship, diversity, values, learning in a global context, and sustainable development (Wu \& Geo-Jaja 2016). This 'bottom-up' approach to create the content of curriculum is indispensable because it opens a space to contest what constitutes knowledge and addresses the enduring legacy of colonialism that haunts schooling in the global south. It also helps to locate learning at the heart of a decolonial approach to reach the possibility of non-Eurocentric modes of education. Yet, given that the overheated planetary crisis that will continue 
to confront the lifespans of the authors and readers of this text, and those lifespans that go beyond ours, there are additional touchstones of how a childist, decolonial analysis of rights in education should unfold in our view.

The unprecedented case (Earth Justice 2019) filed by a transnational collective of 16 young climate activists including Greta Thunberg under the United Nations Convention on the Rights of the Child (UNCRC), asserts that the climate crisis is a children's rights crisis in so far as high carbon-emitting economic policies are violating the rights guaranteed to children by the UNCRC, for example the right to life, health and prioritizing the best interest principle. Complementary to this (and similar climate litigation cases filed by legal minors across the world) are courageous acts of non-violent civil disobedience, organised globally under the umbrella of the Fridays for Future movement, which appeal to profound pedagogical concerns that are directly linked to the rights of the future generation, environmental sustainability and post-colonial global inequity, for example by asking, "Why study for a future if there is no future?" (Biswas \& Mattheis 2021). Their question not only evokes the crisis of existentialism heightened by a capitalist system that is under the verge of collapse, but also the childist dimension of deep interdependence (e.g. Joseffson \& Wall 2020) and communities of care. Nobel peace prize winner Malala Yousafzai's advocacy for education that resonates with girls' aspirations is another example of how young people are performing an educational task for their communities that 'adultist' educational structures of instrumental schooling fail to do. Given these and other struggles for climate justice and educational justice (e.g. Elaw 2017; EAUC 2020; Climate Case Chart 2020); it is time to recognize the inseparable question of childhood and education, acknowledging children as future-makers seriously (Spyrou 2020) and considering how to enable their role in education for community formation.

Moving with the 'relational ontological turn' in critical childhood studies (Spyrou 2018; Spyrou et al. 2019) we understand 'education' as essentially an intergenerational relationship (see also Hoveid \& Hoveid 2019). While education involves an intergenerational transfer of knowledge, values, and skills, we find that it also needs to be a reciprocal and co-generational process in order to enable younger generations to be active parts of community formation. By co-generational, we refer to a childist understanding of educational relationality that moves away from the hierarchy of adults as teachers and children as learners to instead fostering horizontal educational practices, with children and adults as co-learners. For example, by opening up to the philosophical richness that awaits adults if they participate in children's playfully constructed worlds as guests (Biswas 2020) or the courageous ways of socio-political civic engagement that adult citizens can learn from young activists who choose to go on school strike to fight for intergenerational climate justice, despite the harsh adultist reactions they must face (Biswas \& Mattheis forthcoming) or in a broader socio-political sense involving questions of right to stay put (Aitken 2018) and how city governance could be directly realized with children's participation and perspectives (Sundhall 2017).

There is also a need for a shift from looking at intergenerational learning within families to harness the potential for extrafamilial places of intergenerational encounters as sites of learning (Mannion 2018). A relational view on rights in education focuses on intergenerational dimensions of learning in interrelated contexts and spheres of life. It includes learning that takes place, yes, in schools and playgrounds, lecture theaters, and within school buildings but also with peers or siblings 'at home', on-line (in virtual spaces) and, most intriguingly, through embodied mobilities (in cars, on trains, and while walking, climbing, and playing) (Abebe \& Waters 2017). Yet, there is a sense that learning, in part, depends upon involvement in various activities: while herding, farming the fields, trading in the marketplace, or at weddings and festivities and funerals. Rights in education also entails problemsolving and transformative education which are predicated on designing programs nested in progressive ideas of learning for the future. It foregrounds intergenerational dimensions of sociomaterial practice and learning, including in issues such as children's rights and participation, and in wider society as it faces ecological and other challenges (Mannion 2018,314). While such a view of the intertwined question of education and childhood strongly resonates with the relational ontological turn in critical childhood studies, the childist lens particularly demands that the adult-as-teacher and child-as-learner hierarchy does not reproduce itself while 'putting the child back' into processes of community formation. 


\section{Making a case for pluralist indigenous philosophies of childhood and education}

Rights in education engenders the revitalization of indigenous knowledge and educational features that were rendered meaningless by colonial and neoliberal conditions. It calls forth the imagining of an inclusive education that is responsive to the subjectivities, contexts, and needs of multiple generations, addressing such questions as what education as community formation implies. Our engagement with questions of rights in education not only bring to light issues of resistance to an unproblematized acceptance of school curriculum but also the need re-politicize knowledge, schooling, and learning in order to reintroduce them in the debates on educational justice as part of a larger global concern with epistemic (in)justice. On a pragmatic level this includes acknowledging the pedagogical significance and reactivating practices such as multilingualism, musical performance, and ways of transmitting collective memories like rituals, oral history, folklore, dance, art, handicrafts, proverbs, poetry, drama as well as architectures and technology that reflect the histories, cultures, and identities of pre-colonial societies (Tedla 1995). On a philosophical level, this includes confronting the history of philosophical racism that has also seeped into philosophical commitments that underlie what constitutes 'being educated' and 'being knowledgeable' across the globe today. In our view, a way of confronting this history is by broadening scholarly and social pathways to rely on pluralist indigenous philosophies to re-imagine education, childhood and future.

An example of a pluralist indigenous philosophy that embeds interdependent existence and can be helpful to understand how rights in education, childhood and the future are intertwined is Ubuntu. Ubuntu represents the worldviews of indigenous black populations of Sub-Saharan Africa, transmitted from generation to generation through observation, experience, language, and art. The widely acknowledged maxim 'I am who I am because of who we all are' indicates that a pluralistic relationality is at the core of what it means to be a human being. The worldview of Ubuntu reveals that "what happens to the individual happens to the whole group, and whatever happens to the whole group happens to the individual" (Mbiti 1969, 106). Ubuntu is about socialization, that is, how one would not know how to think, walk, speak, or behave unless s/he has learned it from others. At the same time, it is also about the spiritual dimensions of how a person needs other human beings to be human (Tutu 2004, 25). Ubuntu relationality is pluralistic as it is not about 'I am ....because you are' but rather 'I am ....because WE are'. Ubuntu suggests that - like every member of the family and community - children develop personhood through social interactions, which means that they must "prize communal and harmonious relationships with others" (Metz 2016, 324). This emphasis on the community over the individual does not reject the individual but acknowledges that the two are co-creators, interdependent, and mutually sustaining (see Chilisa 2020). This implies that adults also realize their personhood through relationships with children, making room for a co-generational understanding of education for sustainable futures.

The philosophy of Ubuntu is consistent with the ideals of education for sustainable futures in so far as it emphasizes values of interconnectedness, including interpersonal values (regards for others); intrapersonal value (regard for self) and environmental values (regard for the environment) (Maphala 2017). We find that it serves a pertinent role to help us grasp pluralistic relationalities, human-nature interaction and sustainable co-generational futures. Serpell and Adamson-Holley (2017) further invite us to think about how the African traditional practice of assigning social responsibility to children from an early age is highly compatible with contemporary goals (if not practices) of education elsewhere. Their argument is that African societies prime children to learn about sustainability and interdependence: knowledge about agriculture, environment, nutrition, sibling care and so on are not only part of learning and socialization that school curricula overlook but also necessary for cultivating social responsibility and peaceful coexistence. In calling for educational reforms, one 'bottom-up', 'active learning' educational strategy they found to be productive is what they call the 'child-to-child approach' (Serpell \& Adamson-Holley 2017). These forms of knowledge and strategies of learning push us into a space outside the binding strictures of the classroom as well as adults as educators.

Yet, in arguing for education that reflects local and indigenous knowledge systems one needs to be careful in how one advocates instilling pride in 'local' traditions, which can very quickly escalate to large scale nationalisms. Sometimes such traditions need to be challenged in order to promote progressive social change, to redress the intersectional, hierarchical relations between classes, 
genders and generations, exclusive injustices towards ethnic minorities, the differently casted and abled, and to resolve conflict between ethnic and religious groups. In other words, we recognize the philosophical value of Ubuntu for a decolonial, childist approach to global education, but we exercise caution in so far as we do not automatically favor 'local pride'. This is not the least because all forms of knowledge are in some ways 'local' but shared across space and over time.

Another example of an extra-familial site of decolonial learning is education in spiritual contexts. By spiritual learning, we imply the connection of humans with nature as well as a metaphysical appreciation of the significance of traditions and affirmation of all life as a powerful, culturally motivating force. What it means to be an educated person or a critical learning subject in spiritual settings differs from how the dominant western model of schooling views the child as a 'tabula-rasa' learner. Across sub-Saharan Africa (as in most parts of the world), for example, western style schooling replaced diverse forms of education that emphasize spirituality - and religious education as well. Schooling in sub-Saharan Africa is practiced as an antipode to, not alongside with, religious learning such as Qur'anic education, which traditionally were the main sources of knowledge, literacy skills, and ethos of life for children as community members. Such forms of education are based on different understanding of the purpose and goals of life, which include education, how to be critical learner as well as the meaning of children and childhood. Islamic educational practices view children as a divine gift to be honored as part of the spiritual practices of adults too. In the age-old educational practices of the Ethiopian Orthodox Church, the child is viewed as spiritually endowed and as possessing capacities that in certain ways exceed those of adults. The 'Rinponche children' of the Tibetan Buddhist traditions (e.g., the Dalai Lama as a child) are similarly viewed as having onto-epistemological capacities that exceed those of most adults. In addition to how children may be viewed, another defining dimension of spiritual contexts is the relationship between the 'living' and the 'non-living'. While 'western schooling' limits the value of inanimate objects to their usefulness for human beings, indigenous worldviews understand life and resulting human-nature relationality in a wider sense. Such views are not limited to the African or Asian continent but are also found, for example, in the indigenous Sami spirituality of Northern Scandinavia too (Bunikowski 2015). Yet, doing away with spirituality as part of the 'western' secularization project instigates educational structures that chronically compromise on spiritual sensibilities that allow children to navigate the social, moral and emotional landscapes of their societies throughout their lifespans. We view this as a 'global epistemological loss' which is not restricted to societies in the global south like those that Ansell and colleagues (2020) have studied. This is an important and often overlooked point; because spiritual learning is not just integral to children's wellbeing and well becoming but it also enables them to develop meaningful and satisfying lives and fit constructively into their societies. Article 27 of the UNCRC is particularly relevant here as it explicitly recognizes the role of spiritual development not only in the realization of children's 'full potential' and to flourish as human beings but also as integral to an 'adequate standard of living'. We often witness child rights advocates (who seem to rely on the 'ideal white pupil' imagination) drawing attention to the cultural reasons why children's rights to education are not fulfilled or the political economic and material deprivation that hinders effective learning in schools. However, what is neglected is how children realize rights in education and develop reciprocal and meaningful lives, as well as find happiness within a supportive community of educators outside formal schools, including in spiritual contexts (Bourdillon 2014).

With the above examples we demonstrate that it is necessary to make in-roads into pluralist indigenous philosophies of childhood and education by tapping into non-colonial histories and use historical knowledges as inertia to move forward progressively. The examples reveal the significance of the past in the present, invoking the notion of Sankofa - a West African (Akan) concept that means 'to go back and fetch' - lending interpretation for why history matters and its contemporaneity in the present-day lives and experiences of childhoods (Tedla 1995). Having said that, the challenge for a childist decolonial engagement remains that, in pursuing pluralist indigenous philosophies and revitalization of the 'global epistemological loss' which is a direct consequence of colonialism; one does not succumb to a regressive, adult-centric intergenerational ideal of education. What then could be some progressive decolonial childist strategies to re-imagine education as community formation that takes children as future-makers seriously? 


\section{Reimagining education as community formation}

Ansell and colleagues' (2020) critique of schooling and the manipulation of aspiration that disappoint today's generation of children and the wider society has ushered us to reflect upon the issue of 'what beyond' school systems globally. Their comparative empirical insights presented have been impulses for us to connect ideas about educational philosophies, childhood, and the future as well as reimagine education that attends to the question of generational segregation. We think that the unjust crisis highlighted should not be tackled as solely a 'global south' issue but must be considered as part of a north-south continuum. The critique of schooling that is implicit in the climate protests of privileged children in the global north in conjunction with the dysfunctional implementations of the 'right to education' in the global south led us to discuss 'schooling' through the decolonial lens of epistemic injustice. The resulting global epistemological loss of various pluralistic indigenous philosophies that could have guided educational practices is related to the upkeep of 'an ideal white school child' whose present time is systematically claimed in the name of an education for a future that deters her from negotiating that future. Rights in education, seems to be a promising framework for further engagement for decolonial responses. However, we remain alert that proceeding on a decolonial note that simultaneously minimises adult-child power hierarchies is a key hurdle in reimagining education as community formation. In this concluding section, we lay out four preliminary strategies of moving forward with a decolonial, childist lens of reimagining education as community formation.

The first strategy is restructuring and reclaiming the spatio-temporality of global childhoods. Since schooling and its conspirator - capitalism - ejected children out of community forming economies by separating social reproduction from that of economic production (e.g. Katz 2004), there is a need to reclaim the space and time of childhood to develop children's situated learning by facilitating their participation in familial and community livelihoods. This appears to be too obvious a point to make but it is an indispensable one. For example, learning through laboring-with-others is an integral part of children's identity and gives value to what it means to be a child in diverse socio-cultural contexts of the global south. It increases children's learning experiences through observation, the contribution of material value so vital to the sustenance of life as well as the transference of complexly valued and valuable skills that are rendered useless through schooling. This realization further persuades us to consciously partake in the decolonial project by imagining education that does not take children out of community forming economies. However, such practices need to be situated not only in the project of relevant and useful education but also in the re-conceptualization of intergenerational education as a co-generational exercise.

The second strategy is altering the global economic and political structures, including moving away from capitalism as the modus operandi for which schooling is in service. As Ansell and colleagues (2020) highlight, without schooling the capitalist system that creams off profit from the precarious labor market would not exist. This implies that the strategies of education for the future cannot be separated from delinking schooling from capitalism as well as the wider political and economic structures of neoliberalism. This strategy also requires models of education that disengage from western ideologies of international development that equate schooling with education. Among other possibilities, such model should be realized with pluralist indigenous philosophies of childhood and education because they offer very rich spiritual understandings of the meaning of life as well as human-nature relationships. We also call for reimagination of education and learning beyond its curriculum to incorporate a temporal dimension knowledge sharing/transmission in which, for example, ancestral knowledge and philosophies such as Ubuntu are linked with the knowledge and philosophies of the ancestors that the present generation will become. In other words, a reimagination of children's education and futures to unfold not in a linear sequence but rather as an interlocking of pasts, presents, and futures or in which past and future resonate in the present.

The third strategy is to make existing institutions and educational systems work. This can be achieved, for example, through cultivating educational practices for multiple generations and fostering intergenerational learning encounters in familial and community settings. In the global south, this might entail connecting more fully with aspects of learning that are situated in everyday livelihoods in which multiple generations take part. Apprentice education can be one platform for intergenerational 
relating and learning. However, it requires systematic planning and adequate political will and economic investment to facilitate its efficacy in transferring skills and knowledge across generations. In the global north, the existing institutional settings of kindergartens and old homes can be used as intergenerational learning sites where education and care for children and aging populations are combined. Such intergenerational learning centers can potentially facilitate reciprocal learning and co-generational care for early childhood and old age, enhancing the reality of generational interdependence.

Finally, whereas there are aspects of education that can be adapted to local realities; we need to rethink the inseparable imaginations of childhood and education afresh, and address questions that engender rights in education for the future, in both the global south and the global north. Promoting rights in education for community formation is entwined with questions of educational policies and practice. In tandem with fostering co-generational learning, there can be, for example, development of policies for non-formal education where children actively acquire skills alongside other generations outside schools. National educational policies could support shared community conceptions of a good life that are culturally enriching and morally and ethically justifiable. They could also promote diverse forms of education devised with children so that their learning is geared towards and is responsive to the wider cultural, socio-economic and political changes within their societies and beyond. The important role of language in schools and other contexts of education and in preparing children and young people to deal with transient livelihoods cannot be overemphasized.

We propose these outlines to invite future discussions and debates on rights in education by stakeholders of education including governments, international development actors, communities, families as well as children and young people in different spatial scales and contexts.

\section{References}

Abebe, T. (2011) Gendered work and schooling in rural Ethiopia: exploring working children's perspectives In Evers, S. Notermans, C. \& van Ommering, E. (eds.) Not Just a Victim: The Child as Catalyst and Witness of Contemporary Africa, 147-171. https://doi.org/10.1163/ej.9789004204003.i-276.56

Abebe T. (2015) Political economy of children's work: economic restructuring, the coffee trade and social reproduction in post-Socialist Ethiopia. In Ansell N., Klocker N., Skelton T. (eds.) Geographies of Global Issues: Change and Threat. Geographies of Children and Young People, vol 8, 1-22. Springer, Singapore. https://doi.org/10.1007/978-981-4585-95-8_24-1

Abebe, T. (2020) Lost futures? Educated youth precarity and protests in the Oromia Region, Ethiopia. Children's Geographies 18(6) 584-600. https://doi.org/10.1080/14733285.2020.1789560

Abebe, T. \& Waters, J. (2017) Geographies of laboring and learning: Introduction. In Abebe, T., Waters, J. \& Skelton T. (eds.) Labouring and Learning. Geographies of Children and Young People, vol 10, 1-17. Springer, Singapore. https://doi.org/10.1007/978-981-287-032-2 25

Aitken, S. (2018) Young People, Rights and Place: Erasure, Neoliberal Politics and Postchild Ethics. Routledge, New York and London. https://doi.org/10.4324/9781315519258

Ansell, N. P., Froerer, R., Huijsmans, C. E., Dungey, A., Dost, P. \& Piti (2020) Educating 'surplus population': uses and abuses of aspiration in the rural peripheries of a globalising world. Fennia 198(1-2) 17-38. https://doi.org/10.11143/fennia.90756

Biesta, G. J. (2015) Good Education in an Age of Measurement. Ethics, Politics, Democracy. Abingdon, Oxon and Routledge, New York.

Biswas, T. (2020) Little Things Matter Much - Childist Ideas for a Pedagogy of Philosophy in an Overheated World. Büro Himmelgrün, Munich.

Biswas, T. \& Mattheis, N. (2021) Strikingly educational: a childist perspective on children's civil disobedience for climate justice. Educational Theory and Philosophy [online Feb 4 2021] https://doi.org/10.1080/00131857.2021.1880390

Biswas, T. \& Sharma, R. (forthcoming) Will future Ladakhi monks be happy monks? A need for dialogue concerning a special pedagogy for child monks. In Illman, K. \& Schäfer, A. (eds.) Emerging Ladakh. Identity and Belonging in the Context of Increasing Changes. Center for Interdisciplinary Area Studies, Halle.

Bourdillon, M. (2014) Neglected dimensions of child well-being. Children's Geographies 12(4) 497-503. https://doi.org/10.1080/14733285.2014.953315

Bunikowski, D. (2015) Sámi reindeer husbandry as a way of life: on culture, philosophy, cosmology, and law. In Koivurova, T. \& Hasanat, W. (eds.) Current Developments in Arctic Law 3, 3-6. University of the Arctic Thematic Network on Arctic Law, Rovaniemi. 
Chilisa, B. (2020) Indigenous Research Methodologies. $2^{\text {nd }}$ ed. Sage, Los Angeles, CA.

Clemens, I. \& Biswas, T. (2019) Rethinking education in times of globalization - but where to start the rethinking? In Clemens, I., Hornberg, S. \& Rieckmann, M. (eds.) Bildung und Erziehung im Kontext globaler Transformationen, 237-250. Barbara Budrich, Leverkusen. https://doi.org/10.2307/j.ctvm201r8.17

Climate Case Chart (2020) Youth for climate justice v. Austria, et al. <http://climatecasechart.com/ climate-change-litigation/non-us-case/youth-for-climate-justice-v-austria-et-al/> 27.4.2021

Durham, D. (2017) Elusive adulthoods: introduction. In Durham, D. \& Solway, J. (eds.) Elusive Adulthoods: The Anthropology of New Maturities, 1-38. Indiana University Press, Bloomington, IN. https://doi.org/10.2307/j.ctv3hvcd1.4

Earth Justice (2019) Communication to the Committee on the Rights of the Child: in the Case of Chiara Sacchi (Argentina); Catarina Lorenzo (Brazil); Iris Duquesne (France); Raina Ivanova (Germany); Ridhima Pandey (India); David Ackley, lii, Ranton Anjain, And Litokne Kabua (Marshall Islands); Deborah Adegbile (Nigeria); Carlos Manuel (Palau); Ayakha Melithafa (South Africa); Greta Thunberg And Ellen-Anne (Sweden); Raslen Jbeili (Tunisia); \& Carl Smith And Alexandria Villaseñor (Usa); Petitioners, V. Argentina, Brazil, France, Germany \& Turkey. <https://earthjustice.org/sites/default/ files/files/2019.09.23-crc-communication-sacchi-et-al-v.-argentina-et-al-redacted.pdf> . 12.12.2020

EAUC [Alliance for Sustainability Leadership in Education] (2020) English climate emergency education bill launched <https://www.eauc.org.uk/english_climate_emergency education_>. 27.04.2021

Elaw (2017) Petition: Riddhima Pandey v. Union of India (March 2017) <https://elaw.org/petitionridhima-pandey-v-union-india-march-2017> 27.04.2021

Fitzsimons, P. (2002) Enframing education. In Peters, M. (ed.) Heidegger, Education, and Modernity, 171-190. Rowman \& Littlefield Publishers, Lanham.

Hoveid, H. \& Hoveid, M. (2019) Making Education Educational. A Reflexive Approach to Teaching. Springer Nature Switzerland, Cham. https://doi.org/10.1007/978-3-030-27076-6

Jeffrey, C. (2010) Timepass: Youth, Class and the Politics of Waiting in India. Stanford University Press, Stanford, CA. https://doi.org/10.1515/9780804775137

Jeffrey, C., Jeffery, P. \& Jeffery, R. (2005) When schooling fails: young men, education and low-caste politics in rural north India. Contributions to Indian Sociology 39(1) 1-38. https://doi.org/10.1177/006996670503900101

Josefsson, J. \& Wall, J. (2020) Empowered inclusion: theorizing global justice for children and youth. Globalizations 17(6) 1043-1060. https://doi.org/10.1080/14747731.2020.1736853

Katz, C. (2004) Growing Up Global: Economic Restructuring and Children's Everyday Lives. The University of Minnesota Press, Minneapolis.

Katz, C. (2011) Accumulation, excess, childhood: toward a countertopography of risk and waste. Documents d'anàlisi Geogràfica 57(1) 47-60.

Kjørholt, A. T. (2013) Childhood as social investment, rights and the valuing of education. Children and Society 27(4) 245-257. https://doi.org/10.1111/chso.12037

Mannion, G. (2018) Intergenerational education and learning: we are in a new place. In Punch, S. \& Vanderbeck, R. (eds.) Families, Intergenerationality, and Peer Group Relations, Geographies of Children and Young People 5, 307-327. Springer, Singapore. https://doi.org/10.1007/978-981-287-026-1_5

Maphalala, M. C. (2017) Embracing Ubuntu in managing effective classrooms. Gender and Behavior 15 10237-10249.

Mbembe, A. (2016) Decolonizing the university: new directions. Arts and Humanities in Higher Education 15(1) 29-45. https://doi.org/10.1177/1474022215618513

Mbiti, J. S. (1969) African Philosophy and Religion. Heinmann, London.

Metz, T. (2016) Recent philosophical approaches to social protection: from capability to Ubuntu. Global Social Policy 16(2) 132-150. https://doi.org/10.1177/1468018116633575

Nieuwenhuys, O. (1994) Children's Life Worlds: Gender, Welfare and Labor in the Developing World. Routledge, London.

Santos, Boaventura de Sousa (2014) Epistemologies of the South: Justice Against Epistemicide. Routledge, London and New York.

Serpell, R. (2018) Situated understanding of human development in Africa: systematic inquiries at the nexus of psychology, social science and history. Culture \& Psychology 24(3) 382-397. https://doi.org/10.1177/1354067X18779034

Serpell, R. \& Adamson-Holley D. (2017) African socialization values and nonformal educational practices: child development, parental beliefs, and educational innovation in rural Zambia. In Skelton, T., Abebe, T. \& Waters, J. (eds.) Laboring and Learning. Geographies of Children and Young People, vol 10, 19-43. Springer, Singapore. https://doi.org/10.1007/978-981-287-032-2 22

Spyrou, S. (2018) Disclosing childhoods. In Disclosing Childhoods, 1-14. Palgrave Macmillan, London. https://doi.org/10.1057/978-1-137-47904-4_1 
Spyrou, S. (2020) Children as future-makers. Childhood 27(1)3-7.https://doi.org/10.1177/0907568219884142 Spyrou, S., Rosen, R. \& Cook, D. (eds) (2019) Reimagining Childhood Studies. Bloomsbury, London.

Sundhall, J. (2017) A political space for children? The age order and children's right to participation. Social Inclusion 5(3) 164-171. https://doi.org/10.17645/si.v5i3.969

Tedla, E. (1995) Sankofa: African thought and education. Peter Lang, New York.

Teo, T. (2008) From speculation to epistemological violence in psychology: a critical-hermeneutic reconstruction. Theory \& Psychology 18(1) 47-67. https://doi.org/10.1177/0959354307086922

Tutu, D. (2004) God Has a Dream: A Vision of Hope for Our Time. Doubleday, New York.

Wu, X. \& Geo-Jaja, N. (2016) From rights to education to rights in education: a dialogical roadmap for autonomy development. In Geo-Jaja, M. A. \& Majhanovich, S. (eds.) Effects of Globalization on Education Systems and Development, 3-21. SensePublishers, Rotterdam. https://doi.org/10.1007/978-94-6300-729-0 1 